\title{
Canoa: poder y memoria
}

\section{Alberto Balam Navarro-Medina}

A lo largo de la historia, nosotros, como pueblo, hemos demostrado tener miedo al cambio. E1 consuelo que viene con la complacencia y el institucionalismo, cuando se desafía, a menudo se encuentra con duras críticas y agresivos rechazos. En octubre de 1968, la Ciudad de México se convirtió en el epicentro de un movimiento dirigido por estudiantes que ya no se sentían cómodos con la complacencia de una fuerza policial opresiva, la conformidad con un gobierno autoritario y la opresión que durante tanto tiempo había asegurado que quienes estaban en el poder nunca serían desafiados. Un mes antes, en la localidad de San Miguel Canoa, en el estado de Puebla, un grupo de trabajadores universitarios viajaron desde la capital del estado hasta San Miguel Canoa para una excursión de fin de semana. Tanto el movimiento dirigido por estudiantes, como el viaje de senderismo, se convirtieron en algunos de los episodios más oscuros de la historia de México que el gobierno trató activamente de borrar de la historia del país. El manejo por parte del gobierno de estos eventos y las secuelas que siguieron silenciaron a cualquiera que cuestionaba la narrativa oficial proporcionada por el Estado. Habiendo dicho todo esto, la idea de que cualquiera pueda hacer una película comentando directamente o indirectamente sobre estos dos eventos y que sea financiada por el Estado se consideraría absurda. Pero, en 1975, Felipe Cazals haría exactamente eso en la forma de su obra maestra Canoa: A Shameful Memory.

Siento la necesidad de mencionar que mientras investigaba para este trabajo nunca había oído hablar del linchamiento que ocurrió en San Miguel Canoa. Durante mi investigación, el nombre San Miguel Canoa se presentó constantemente en conversaciones y entrevistas con varios de los directores mexicanos más destacados de la actualidad (Del Toro, Cuarón e Iñárritu). Antes de ver la película, no tenía una imagen clara de cómo era México en los años 60 y 70. Mi imaginación y los recuerdos que mis padres compartieron conmigo fueron las únicas herramientas que tenía para pintar una imagen de cómo era la realidad de mis padres cuando tenían mi edad. Durante mi niñez, mi padre me contaba constantemente de sus aventuras de senderismo y montañismo en México. Las pocas fotos que tomó, y que sobrevivieron al paso del tiempo, me dieron una idea de cómo eran sus días de aventuras. Después de terminar la película, me quedé sin palabras después de haber visto no sólo un linchamiento horrible, sino también algo que podría haberle sucedido a mi padre de manera realista.

E1 hecho de que se haga cualquier película es un milagro. El hecho de que se haya hecho esta película, 
dado todo lo que tenía en contra, es una prueba de que hay un Dios. Las películas mexicanas de los años 70 fueron financiadas principalmente por el Estado a través del Banco Nacional Cinematográfico. A los creativos se les ofreció un paquete en el que el gobierno contribuiría con una parte del presupuesto de las películas y el resto tendría que ser cubierto por aquellos interesados en ver la película realizada. Los escritores y directores obtendrían financiamiento vendiendo guiones y lanzamientos al gobierno y esperarían financiar o financiar parcialmente sus proyectos. En aquel momento, el director del banco era Rodolfo Echeverría - también conocido como Rodolfo Landa en películas como La marca del cuervo (1958) y Perdidos autómatas de la muerte (1962). Rodolfo Echeverría era hermano del entonces presidente Luis Echeverría Álvarez, uno de los autores intelectuales de la masacre del 68, autor de la masacre del 71 y creador de la Guerra Sucia mexicana (Meza, 2018).

Rodolfo Echeverría, un exactor, sirvió como una extensión de su hermano y su gobierno autoritario. Sin embargo, era ante todo actor y, como dice el refrán, el espectáculo debe continuar. En el momento en que el cine mexicano atravesaba un período de calma o, como dice Cazals, de pipi (Cazals, 1975), la fórmula anticuada que sirvió de base a muchas películas mexicanas ya no tenía el mismo éxito. Esto dejó a Rodolfo en una situación bastante difícil. “Cómo puedo revitalizar el cine en mi país?” Lo hizo financiando una nueva generación de obstinados directores mexicanos que se negaron a usar la fórmula de antes para contar las historias de hoy. Estos directores ya no estaban interesados en la versión romántica de México y querían retratar una realidad más directa de México. Esta nueva generación la integraron directores como Paul Leduc, Jaime Humberto Hermosillo, Arturo Ripstein, Jorge Fons y Felipe Cazals (Cazals 1975).

En un principio, se suponía que Canoa sería dirigida por Jorge Fons, pero por razones desconocidas, cayó en las manos magistrales del director Felipe Cazals. Si bien la película se centra en los hechos que tuvieron lugar en San Miguel Canoa, sirve como metáfora de los hechos que ocurrieron en todo el país en 1968. Tanto el linchamiento en Puebla como la masacre en la Ciudad de México se plasman en el contexto de la película. El guión de la película fue escrito por Tomás Pérez Turrent, quien pretendía presentar un testimonio del linchamiento. Sus intenciones se ven claramente en la forma en que la película se estructura en un formato de estilo documental. La audiencia está destinada a presenciar los eventos que tuvieron lugar en lugar de entablar relaciones con quienes fueron víctimas del trágico evento. Cazals enfrentó el desafío de retratar con precisión los relatos de los sobrevivientes, pero estaba limitado por lo que el público estaba preparado a ver en pantalla. Por eso es que Cazals utilizó un "distanciamiento brechtiano" para obligar al público a analizar críticamente lo que veía. Lo hizo a través de los ojos de Alex Phillips Jr., director de cinematografía, y con una estructuración poco ortodoxa de la película que era inaudita en ese momento, pero que seguía el guión original de Tomás Perez Turrent (Muñetón, 2019).

La película comienza con un reportero de un periódico que recibe una llamada de un corresponsal local sobre un linchamiento que había tenido lugar en una pequeña ciudad. Es a partir de ahí que vamos a aprendiendo más y más sobre la ciudad, sus habitantes y el sacerdote hambriento de poder que será el artífice del linchamiento. Desde muy temprano conocemos al "testigo", interpretado por Salvador Sánchez, quien informa a la audiencia sobre dinámica de poder dentro del pueblo. "El testigo" no tiene miedo de reconocer directamente la opresión que enfrenta la ciudad y cómo se les pide constantemente para construir 
y desarrollar el pueblo. Uno pensaría que el gobierno local estaría a cargo de todo esto, pero debido a la lejanía del pueblo, en realidad es el cura local y sus conexiones políticas los que dictan qué, cuándo y quién prospera en el pueblo. Este sacerdote, brillantemente interpretado por Enrique Lucero (Los siete magníficos, El grupo salvaje y Butch Cassidy and The Sundance Kid) que sirve como el hombre respetable, el representante de la Iglesia, alguien que no puede ser cuestionado y que no puede ser puesto en duda, que contradice la narrativa que brinda "el testigo".

La película muestra que la narrativa oficial que se publicó en diarios y medios de prensa de todo el país se contradice con la narrativa de la gente del pueblo, o la del "testigo", y nunca forma parte de los hechos ocurridos. Esto, en todo caso, es un comentario sobre la forma en que tanto el relato "oficial" del linchamiento como la masacre en la Ciudad de México fueron completamente controlados por el Estado (Rodríguez, 2018). Dicho esto, la narrativa de esta película continúa haciéndola relevante aún hoy como el secuestro y masacre masiva que tuvo lugar en Ayotzinapa.

Si bien la figura central de la película es sin duda el personaje de Enrique Lucero, Canoa, al igual que la masacre de la Ciudad de México de ese mismo año, y muchas otras que vinieron después, es una pieza de conjunto. Aunque no sepamos los nombres de cada uno de los cuatro mil habitantes de San Miguel Canoa, los que participaron y los que no, somos plenamente conscientes de que por sus acciones o por su falta de acción, el linchamiento y la falta de consecuencias fue posible por la participación de todos. Esto vuelve a demostrar no sólo los hechos ocurridos durante 1968 en México, sino la forma en que el país se ha mantenido complaciente y ha aceptado que esa es su realidad. Para evitar problemas no directamente relacionados con ellos, los involucrados (directa e indirectamente) optan por silenciarse para evitar posibles consecuencias.

La película nos presenta a las víctimas del linchamiento en la ciudad de Puebla. Vemos un grupo de jóvenes empleados universitarios en su lugar de trabajo. No hay nada especial en cómo se les retrata, ni en lo que hacen en la universidad de Puebla. Lo que sí vemos es cómo reaccionan y se sienten sobre el creciente movimiento liderado por estudiantes en la Ciudad de México y la forma en que el Estado presenta una narrativa unilateral sobre lo que realmente está sucediendo. Durante una escena con todas las víctimas en un restaurante, algunos expresan su apoyo al movimiento estudiantil, mientras que otros comentan su temor de lo que les pueda pasar a los estudiantes si las tensiones continúan aumentando. Es entonces cuando empiezan a organizar su viaje de senderismo y empezamos a conocerlos un poco más. Este segmento de la película es una vez más un comentario sobre la situación económica de México en los años 60 y 70 : Estaba surgiendo una clase media próspera y cada vez más familias podían enviar a sus hijos a estudiar en universidades. El país sería sede de los Juegos Olímpicos del verano de 1968, un privilegio que nunca se había otorgado a una nación en vías de desarrollo como México.

Cuando los empleados llegan a San Miguel Canoa, se encuentran con una fuerte tormenta y lugareños abrasivos que son cautelosos con estos jóvenes desconocidos. Como no pueden regresar a Puebla, los empleados buscan refugio para pasar la noche y dan a conocer su presencia al pueblo mientras se dirigen a la iglesia, al ayuntamiento y los comercios locales en busca de un lugar para pasar la noche para luego comenzar su caminata temprano en la mañana. Los empleados universitarios encuentran refugio en una 
pequeña casa después de muchos fracasos, pero para ese entonces todo el pueblo sabía de su presencia y alertó rápidamente al cura.

Utilizando los megáfonos del pueblo, el equivalente de los medios de comunicación de la época, los vecinos más cercanos al cura comienzan a informar al pueblo que los comunistas han infiltrado el pueblo y están planeando colgar una bandera rojinegra en la iglesia. Los empleados son descritos como ladrones y herejes que no planean hacer nada más que cosas malas contra la ciudad y su gente. Esto pone a los lugareños en un frenesí y se forma una masa de alborotadores fuera de la iglesia que comienzan a buscar a los empleados universitarios. Al igual que los eventos de la masacre en la Ciudad de México, las víctimas no hicieron nada para instigar la violencia, fue el Estado, el sacerdote en San Miguel Canoa y el ejército en la Ciudad de México los que iniciaron los disturbios en primer lugar (Rodríguez, 2018). Lo que sigue son escenas horribles sólo comparables a las de una película de terror que muestra el linchamiento brutal de varios de los empleados. Durante el castigo vemos que los empleados miran directamente al cura, ya que no hace nada para detener lo que está sucediendo. Añadiendo además el elemento del pueblo que jugó un rol importante en el linchamiento.

Los empleados son rescatados por las autoridades de Puebla y los pocos sobrevivientes son llevados de regreso a la ciudad para recibir atención médica. El pueblo de San Miguel Canoa se ve obligado a pagar una tarifa a las autoridades superiores y un par de personas se ven obligadas a pasar tiempo en la cárcel. Hacia el final de la película "el testigo" nos informa de los hechos que siguieron al linchamiento y dice lo que mucha gente siente cada vez que sucede algo así: "Estábamos mal ahora estamos peor".

La película tuvo éxito internacional y se llevó muchos premios en festivales de cine internacional. En el México de 1976, la respuesta no fue tan acogedora. La película fue incluida en la lista de películas prohibidas por grupos eclesiásticos conservadores y, curiosamente, recibió pocas críticas por parte de los funcionarios gubernamentales que estaban en poder en ese momento. Si bien esto puede parecer desconcertante, queda muy claro cuando recuerdas quién aprobó la financiación de la película en ese entonces: el hermano del presidente.

La película, en todo caso, es una advertencia sobre los peligros de la complacencia en un estado autoritario. Las víctimas del régimen autoritario del gobierno no eran extremistas políticos, comunistas o anarquistas, sino simplemente estudiantes y empleados de la universidad que querían más de su país. Canoa es sin duda una de las películas más importantes de la historia de México y una que hay que ver para entender el cine mexicano. 


\section{Obras citadas}

Meza, Karen. "Canoa, la verdadera historia a 50 años del linchamiento." El Sol de Puebla, 14 Sept. 2018, www.elsoldepuebla.com.mx/local/video-canoa-la-verdadera-historia-a-50-anos-del-linchamiento-puebla-linchamiento-1995045.html.

Muñetón, Karla. "A 51 años de la masacre de Canoa, Puebla." El Sol de Tlaxcala, 14 Sept. 2019, www. elsoldetlaxcala.com.mx/local/municipios/a-51-anos-de-la-masacre-de-canoa-puebla-4180605.html.

Rodríguez, Moisés Ramos. "Masacre en Canoa: medio siglo de impunidad (Parte I)." Milenio, 14 Sept. 2018, www.milenio.com/cultura/masacre-en-canoa-medio-siglo-de-impunidad-parte-i.

Chrisman, Kevin. Community, Power, and Memory in Díaz Ordaz's Mexico: The 1968 Lynching in San Miguel Canoa, Puebla. Dissertations, Theses, \& Student Research, Department of History, University of Nebraska-Lincoln, 19 Apr. 2013.

Canoa: A Shameful Memory, Director Felipe Cazals, Criterion Collection, 1975, Película. 